\title{
Use of and Interests in Complementary and Alternative Medicine by Hispanic Patients of a Community Health Center
}

\author{
Daniel V. Ho, BS, Jannett Nguyen, BS, Michael A. Liu, BS, \\ Annie L. Nguyen PhD, MPH, and David B. Kilgore, MD
}

Introduction: We evaluated complementary and alternative medicine (CAM) use among a medically underserved, predominately Hispanic community at the University of California Irvine Family Health Center, a federally qualified health center.

Methods: A cross-sectional, anonymous survey assessed patient use of, interest in, and communication preferences concerning CAM.

Results: The 150 respondents primarily self-identified as Hispanic (74\%), were born outside the United States (55\%), were medically insured (56\%), and had a high school education or less (55\%). of these respondents, $63 \%$ used at least 1 type of CAM; the most commonly used were: vitamins/supplements $(32 \%)$, herbal medicine (29\%), dietary/nutritional therapy (26\%), massage (24\%), meditation/ relaxation (15\%) and chiropractic (11\%). Therapies that patients most desired to see provided at the clinic included massage, healthier cooking, guidance on herbs/supplements, and diet/nutrition. Among respondents, $61 \%$ were comfortable disclosing CAM use to physicians, $58 \%$ agreed physicians should have basic knowledge of CAM, and $47 \%$ desired that physicians ask about CAM use.

Conclusions: Results demonstrate that CAM use is common among patients, and a large proportion of patients have interest in accessing CAM through their primary care clinic. Patients recognize the importance of communicating CAM use with their providers and seem receptive to discussing such topics. (J Am Board Fam Med 2015;28:175-183.)

Keywords: Access to Health Care, Alternative Medicine, Primary Health Care; Populations, Underserved

The National Center for Complementary and Alternative Medicine defines complementary and alternative medicine (CAM) as "a group of diverse medical health care systems, practices, and products that are not presently considered to be a part of conventional medicine." Common CAM therapies include vitamins/supplements, herbs, deep breathing exercises, yoga, massage, meditation, and acupuncture. $^{2,3}$

This article was externally peer reviewed.

Submitted 21 July 2014; revised 21 October 2014; accepted 27 October 2014.

From the Department of Family Medicine, University of California Irvine School of Medicine, Irvine.

Funding: This study was funded by University of California, Irvine Grant/Fellowship no. 88023s1 ( to DVH).

Conflict of interest: none declared.

Corresponding author: Daniel V. Ho, BS, Department of Family Medicine, University of California Irvine School of Medicine, 101 The City Drive, Bldg. 200, Suite 835, Orange, CA 92868 (E-mail: dvho91@gmail.com).
The National Health Interview Survey showed a general nationwide increase in CAM use, from $36.0 \%$ in 2002 to $38.3 \%$ in $2007 .^{2,3}$ Analyses of these nationwide surveys indicate that health care access delayed because of cost is closely associated with the rise in CAM use and that patients who lack access to health care are more likely to use CAM than those who do have access to health care. ${ }^{4}$ These findings emphasize the importance of studying medically underserved populations in which CAM use might be more prevalent.

In particular, the Hispanic population in the United States has grown by $50 \%$ since $2000,{ }^{5}$ and this medically underserved ethnic group continues to face barriers to conventional medicine access. ${ }^{6}$ Although previous studies have assessed common CAM modalities used by Hispanic populations, the studies vary widely by scale and survey design. Nationwide surveys conducted through the $\mathrm{Na}$ - 
tional Health Interview Survey reported that Hispanics are the second largest ethnic group to use CAM, with a prevalence of $24 \%$ in $2007 .^{2}$ Focused, smaller-scale studies tend to show a higher prevalence of CAM use among Hispanics. For example, a study that oversampled minority groups showed that CAM use is equally prevalent among all ethnic groups, with $41 \%$ of Hispanics using $\mathrm{CAM}^{7} \mathrm{~A}$ limitation of most studies' designs was that patient surveys were available in only English. ${ }^{8}$ When multilanguage surveys or interpreters were accessible, a study showed an even higher percentage of Hispanic CAM users (63\%). ${ }^{9}$ Variation in results may also be attributed to different definitions of CAM across studies. ${ }^{10}$ Past studies reported that CAM modalities used among Hispanic populations include herbs, dietary supplements, prayer, meditation, and deep breathing exercises. ${ }^{2,9}$ CAM therapies are used to treat both acute and chronic issues, including pain, headache, lethargy, diabetes, asthma, and high cholesterol. ${ }^{9,10}$ Despite the common use of CAM among Hispanic populations, studies suggest that $>60 \%$ of Hispanic patients do not disclose to their physicians information about their CAM usage. ${ }^{11,12}$ Lack of disclosure to physicians presents safety concerns because some CAM practices may deleteriously interact with common allopathic prescription medications. ${ }^{13}$

Though race and socioeconomic status often are closely associated, the latter has been suggested as the stronger determinant of primary health care use in the United States. ${ }^{14}$ This highlights the importance of assessing not only Hispanic individuals but also the medically underserved of other racial backgrounds. This study focused on the medically underserved, predominately Hispanic community in Orange County, California, who obtain health care services at the University of California (UC) Irvine Family Health Center (FHC). While other studies have assessed CAM use and attitudes toward communicating with their providers about CAM, this study also uniquely explores patients' interest in accessing CAM therapies at their primary care clinics. Because CAM is increasingly being used to treat chronic illnesses, ${ }^{15,16}$ studying CAM use in a primary care medical setting in which physicians are responsible for managing chronic conditions is important. The overall goal of this study was to learn about patient preferences for CAM use and communication. Our aims were to (1) assess the specific types of CAM modalities used by patients,
(2) determine the types of CAM services that patients would like to access through the clinic, (3) determine patients' attitudes toward discussing CAM use with their providers, and (4) compare preferences and attitudes between CAM users and nonusers and persons born inside and outside the United States. The results of this study can assist primary care clinics and other federally qualified health centers with similar patient populations to assess potential CAM modalities for implementation at their centers and provide health care providers with the tools and information to deliver comprehensive, proper patient care.

\section{Methods}

A cross-sectional, 13-item print survey was distributed at the UC Irvine Santa Ana FHC from May 2013 to August 2013. The FHC is a federally qualified health center and the largest provider of comprehensive primary care in Orange County. The clinic serves a largely Hispanic medically underserved population; $>90 \%$ of patients fall below $200 \%$ of the federal poverty level. The majority of patients are insured through Medicaid or the Medical Services Initiative, a federal-, state-, and countyfunded health care program that provides medical care for Orange County's low-income citizens. Approximately $12 \%$ of patients lack any form of insurance. Hispanic patients make up a little over $70 \%$ of the overall clinic population.

Patients were eligible for this study if they met the following inclusion criteria: (1) patient at the health center, (2) speaks English or Spanish, and (3) at least 18 years old. Surveys were distributed during clinic hours. Subjects were recruited in the waiting room by trained student volunteers who followed a protocol that fully informed subjects of the contents of the study before participation. Participation in the study was voluntary, and the survey was designed to take no longer than 10 minutes. No incentives were provided. On occasion, participants were unable to complete the survey because of time constraints or lack of interest. These incomplete surveys were securely discarded. English and Spanish versions of the survey were offered to patients. A certified Spanish translator reviewed the Spanish survey to confirm proper translation. A Spanish-speaking interpreter was available upon request or for any patient who was unable to speak English. 
The survey included a set of demographic questions about age, sex, race, place of birth, level of education, and medical insurance. CAM was defined as self-chosen treatments or home remedies used along with treatments prescribed by their doctors, and this definition was provided in text at the start of the survey. For each CAM modality mentioned in the survey, a brief description of the modality was listed to ensure participants had a clear understanding of the terms used. Patients were asked to circle all CAM modalities that they used within the past year and were permitted to write in their own answer if they selected "other." Patients were asked to state any vitamin, herb, or supplement use. Patients indicated their reason for CAM use from a list of chronic diseases, and health reasons for CAM use that were seldom cited were grouped under "miscellaneous" in our results. In addition, patients were asked to circle modalities that they were interested in having offered at the health center. Respondents were given a series of statements regarding communication of CAM usage and were asked to rate statements based on a Likert scale: strongly disagree, disagree, no opinion, agree, and strongly agree. Survey questions were derived under the guidance of the principal researcher (DBK), a clinical professor of family medicine and director of UC Irvine's Integrative Medicine Residency Track at the FHC. The study was approved by the UC Irvine Institutional Review Board.

Data analysis was conducted using SPSS Statistics software version 22 (IBM, Chicago, IL). Descriptive statistics were summarized in frequency values and percentage responses with $95 \%$ confidence intervals (CIs). The $\chi^{2}$ test of proportions or the Fisher exact test were performed to compare differences between (1) CAM users and nonusers, (2) Hispanics and non-Hispanic whites, and (3) persons born inside and outside the United States. The $\alpha$ level for significance was set to 0.05 for this study.

\section{Results}

The response rate was approximately $70 \%$; a total of 150 patients completed the survey. Table 1 summarizes the demographic characteristics of the study's respondents: 97 (65\%) of participants were women and $52(35 \%)$ were men. The mean age of participants was $41 \pm 14$ years. The population
Table 1. Sociodemographic Characteristics of Surveyed Patients at University of California Irvine Family Health Center, May through August 2013 ( $\mathrm{n}=150)$

\begin{tabular}{|c|c|}
\hline Characteristics & Respondents, \% (n) \\
\hline \multicolumn{2}{|l|}{ Sex } \\
\hline Male & $35(52)$ \\
\hline Female & $65(97)$ \\
\hline \multicolumn{2}{|l|}{ Age (years) } \\
\hline $18-29$ & $25(37)$ \\
\hline $30-39$ & $24(35)$ \\
\hline $40-49$ & $22(33)$ \\
\hline $50-59$ & $17(25)$ \\
\hline$\geq 60$ & $12(18)$ \\
\hline \multicolumn{2}{|l|}{ Ethnicity } \\
\hline Hispanic/Latino & $74(108)$ \\
\hline Non-Hispanic white & $16(23)$ \\
\hline Asian & $6(9)$ \\
\hline African American & $3(4)$ \\
\hline Other & $2(3)$ \\
\hline \multicolumn{2}{|l|}{ Birthplace } \\
\hline United States & $45(64)$ \\
\hline \multicolumn{2}{|l|}{ Not United States } \\
\hline Mexico & $31(44)$ \\
\hline Central America & $2(3)$ \\
\hline Other & $5(7)$ \\
\hline Did not specify (non-U.S. location) & $17(25)$ \\
\hline \multicolumn{2}{|l|}{ Education } \\
\hline Elementary & $11(16)$ \\
\hline High school & $45(67)$ \\
\hline College & $41(62)$ \\
\hline Postgraduate & $3(5)$ \\
\hline \multicolumn{2}{|l|}{ Medical Insurance } \\
\hline Yes & $56(83)$ \\
\hline No & $44(66)$ \\
\hline
\end{tabular}

primarily identified themselves as Hispanic (74\%), born outside of the United States (55\%), medically insured (56\%), and having a high school education or less $(55 \%)$. No significant differences in demographic backgrounds between CAM users and nonusers were found. Compared with non-Hispanic whites, Hispanics in our study showed significant differences in medical insurance (49\% vs $74 \% ; P=$ $.047)$, being US born (32\% vs. $87 \% ; P<.01)$, and college education $(31 \%$ vs. $87 \% ; P<.01)$.

\section{CAM Use in the Past Year}

Table 2 summarizes the respondents' use of CAM modalities. Of the 150 patients who responded to the survey, 94 (63\%; $95 \%$ CI $55 \%$ to $70 \%)$ re- 
Table 2. Complementary Alternative Medicine Modalities Used Within the Last Year by Total Respondents ( $\mathrm{n}=150,240$ Responses), US-Born Respondents ( $\mathrm{n}=64,106$ Responses), and Non-US-Born Respondents ( $\mathrm{n}=79,121$ Responses)

\begin{tabular}{|c|c|c|c|}
\hline Type of Modality & Total Respondents* & US-Born Respondents* & Non-US-Born Respondents* \\
\hline Vitamins/supplements & $32(48)$ & $31(20)$ & $33(26)$ \\
\hline Herbal medicine & $29(43)$ & $27(17)$ & $29(23)$ \\
\hline Dietary/nutritional therapy & $26(39)$ & $41^{\dagger}(26)$ & $17(13)$ \\
\hline Massage & $24(36)$ & $22(14)$ & $24(19)$ \\
\hline Meditation/relaxation exercises & $15(23)$ & $19(12)$ & $11(9)$ \\
\hline Chiropractic & $11(16)$ & $11(7)$ & $10(8)$ \\
\hline Acupuncture & $7(11)$ & $5(3)$ & $9(7)$ \\
\hline Yoga & $7(11)$ & $8(5)$ & $6(5)$ \\
\hline Cupping & $3(5)$ & $2(1)$ & $5(4)$ \\
\hline Energy healing & $2(3)$ & $2(1)$ & $3(2)$ \\
\hline Coining & $1(1)$ & $0(0)$ & $1(1)$ \\
\hline Curanderismo & $1(1)$ & $0(0)$ & $1(1)$ \\
\hline Tai chi & $1(1)$ & $0(0)$ & $1(1)$ \\
\hline Espiritismo & $0(0)$ & $0(0)$ & $0(0)$ \\
\hline Hypnosis & $0(0)$ & $0(0)$ & $0(0)$ \\
\hline Santería & $0(0)$ & $0(0)$ & $0(0)$ \\
\hline Other & $1(2)$ & $0(0)$ & $3(2)$ \\
\hline
\end{tabular}

Data are \% (n).

* Respondents were allowed to list more than one complementary alternative medicine modality.

${ }^{\dagger} P<.01, \chi^{2}$ test, US-born vs non-US-born respondents.

ported using at least 1 type of CAM modality within the last year. Vitamins/supplements $(32 \%$; 95\% CI, 25-40\%), herbal medicine (29\%; 95\% CI, $22-36 \%)$, dietary/nutritional therapy $(26 \% ; 95 \%$ CI, $19-33 \%)$, and massage $(24 \%$; $95 \%$ CI, $17-$ $31 \%$ ) were most frequently used. Other commonly used treatments include meditation/relaxation techniques, chiropractic, yoga, and acupuncture. CAM modalities indicated in this study with limited $(<1 \%)$ or zero use include coining, hypnosis, tai chi, curanderismo, espiritismo, and Santería. There was a significant difference in the use of dietary/ nutritional therapy between US-born and non-USborn CAM users ( $41 \%$ vs $17 \%$; $P<.01$ ).

\section{Use of Herbs, Vitamins, and Supplements}

Table 3 summarizes the most common herbs, vitamins, and supplements used by the surveyed patients. At least 1 type of herb, vitamin, or supplement was used for health purposes by 55 respondents (37\%; 95\% CI, 29-44\%). Of these respondents, the most frequently used vitamins and supplements include multivitamins (42\%; 95\% CI, $29-55 \%)$, omega-3 fish oil (24\%; 95\% CI, $13-$ $35 \%$ ), calcium (20\%; 95\% CI, 9-31\%), and vita- min C (11\%; 95\% CI, 3-19\%). The top choices for herbs include herbal tea (24\%; 95\% CI, $13-35 \%)$, chamomile (11\%; 95\% CI, 3-19\%), lemon (11\%; 95\% CI, 3-19\%), and mint (9\%; 95\% CI, $1-17 \%$ ).

\section{Health Reasons for Using CAM}

The primary health reasons for the use of CAM among respondents $(\mathrm{n}=71)$ consist of weight loss (37\%; 95\% CI, 26-48\%), sleep (27\%; 95\% CI $17-37 \%)$, diabetes (23\%; 95\% CI, $13-32 \%)$, pain (20\%; 95\% CI, 10-29\%), high blood pressure (18\%; 95\% CI, 9-27\%), indigestion (16\%; 95\% CI, 7-24\%), lack of energy (9\%; 95\% CI, 2-15\%), and miscellaneous reasons such as colds, coughs, and stress (20\%; 95\% CI, 10-29\%).

\section{Interest in Therapies Offered at the Health Center}

Table 4 summarizes the surveyed patients' interests in specific potential therapies offered at the clinic. The majority of respondents $(72 \% ; 95 \%$ CI, 65-79\%) were interested in having additional resources offered at the health center. CAM users selected more CAM therapies for integration than non-CAM users (1.89 vs 1.16 mean selections; $P<.01)$. Therapies involving food and 
Table 3. Most Common Herbs, Vitamins, and Supplements Used by Respondents $(\mathrm{n}=55)$

\begin{tabular}{lc}
\hline $\begin{array}{l}\text { Common Vitamins, Supplements, and } \\
\text { Herbs Used }\end{array}$ & $\begin{array}{c}\text { Respondents, } \\
\%(\mathrm{n})\end{array}$ \\
\hline Vitamins/supplements & \\
Multivitamins & $42(23)$ \\
Omega-3 fish oil & $24(13)$ \\
Calcium & $20(11)$ \\
Vitamin C & $11(6)$ \\
Vitamin B & $9(5)$ \\
Vitamin D & $9(5)$ \\
Iron & $6(3)$ \\
Herbs & \\
Herbal tea & $24(13)$ \\
Chamomile & $11(6)$ \\
Lemon & $11(6)$ \\
Mint & $9(5)$ \\
Aloe vera & $4(2)$ \\
Garlic & $4(2)$ \\
Milk thistle & $4(2)$ \\
\hline
\end{tabular}

*Respondents were allowed to list more than one type of herb, vitamin, or supplement.

diet, such as classes in healthier cooking (35\%; 95\% CI, 28-43\%), classes in personal diet and nutrition (33\%; 95\% CI 25-40\%), and guidance in herb and supplements use $(18 \% ; 95 \%$ CI, $12-24 \%$ ) were commonly chosen by both CAM users and nonusers. Massage (30\%; 95\% CI, $23-$ $37 \%)$, mind-body relaxation techniques (16\%; 95\% CI, 10-22\%), yoga (13\%; 95\% CI, 8-19\%), and acupuncture (11\%; 95\% CI, 6-16\%) also were frequently chosen.

\section{Communication With Health Providers About CAM \\ Use}

Table 5 describes the surveyed patients' opinions regarding CAM communication with their respective health care providers. More than half of all respondents either strongly agreed or agreed that they were comfortable disclosing their CAM use (61\%; 95\% CI, 53-69\%) and with seeing a CAM practitioner (57\%; 95\% CI, 49-65\%). In addition, more than half of the respondents agreed that their physician should have basic knowledge of CAM (58\%; 95\% CI, 50-67\%). Of respondents, 47\% (95\% CI, 39-55\%) would like their physician to ask about their current CAM usage. Response choices regarding comfort disclosing CAM use to physicians, comfort disclosing to physicians visits to a CAM practitioner for treatment, preference for physicians' knowledge of CAM, and preference for physician-initiated CAM discussion were significantly different between CAM users and non-CAM users. The majority of CAM users strongly agreed or agreed with the statements, whereas most nonusers had no opinion. No significant differences in CAM communication preferences were found between US-born and non-US-born respondents.

\section{Discussion}

Vitamins/supplements and herbal medicine were the most common CAM modalities used by our population. Prior studies of predominantly Hispanic populations showed similar patterns of CAM therapy use. ${ }^{9,17-20}$ A large California statewide health survey also reported that vitamins/supple-

Table 4. Therapies Total Respondents $(n=150,241$ Responses), US-Born Respondents $(n=64,100$ responses), and Non-US-Born Respondents $(n=79,134$ Responses) Were Interested in Having Offered at the Health Center

\begin{tabular}{lccc}
\hline Type of Therapy & Total Respondents* & US-Born Respondents* & Non-US-Born Respondents* \\
\hline Classes for healthier cooking & $35(53)$ & $33(21)$ & $38(30)$ \\
Informational classes on personal diet and nutrition & $33(49)$ & $33(21)$ & $35(28)$ \\
Massage & $30(45)$ & $27(17)$ & $33(26)$ \\
Guidance in taking herbs and supplements & $18(27)$ & $19(12)$ & $19(15)$ \\
Mind-body (meditation) relaxation techniques & $16(24)$ & $13(11)$ & $14(11)$ \\
Yoga & $13(20)$ & $11(7)$ & $14(11)$ \\
Acupuncture & $11(16)$ & $3(2)$ & $3(2)$ \\
Tai chi & $3(4)$ & $2(1)$ & $3(2)$ \\
Other & $2(3)$ & $(2)$ & \\
\hline
\end{tabular}

Data are \% (n).

*Respondents were allowed to choose more than one therapy. 
Table 5. Total Respondents', Complementary Alternative Medicine Users', and Non-Complementary Alternative Medicine Users' Likert-Scale Responses to Statements Regarding Complementary Alternative Medicine Use

\begin{tabular}{|c|c|c|c|}
\hline Response Options & Total Respondents & CAM Users & Nonusers \\
\hline \multicolumn{4}{|c|}{$\begin{array}{l}\text { I feel comfortable telling my doctor about CAM therapies I use } \\
\text { or might use. }\end{array}$} \\
\hline Strongly agree & $17(25)$ & $22^{*}(20)$ & $9(5)$ \\
\hline Agree & $44(64)$ & $56^{\dagger}(50)$ & $26(14)$ \\
\hline No opinion & $37(54)$ & $20^{\dagger}(18)$ & $66(36)$ \\
\hline Disagree & $1(1)$ & $1(1)$ & $0(0)$ \\
\hline Strongly disagree & $1(1)$ & $1(1)$ & $0(0)$ \\
\hline \multicolumn{4}{|c|}{$\begin{array}{l}\text { I would tell my doctor if I went to a CAM practitioner for } \\
\text { treatment. }\end{array}$} \\
\hline Strongly agree & $14(20)$ & $17(15)$ & $9(5)$ \\
\hline Agree & $43(61)$ & $52^{\dagger}(47)$ & $26(14)$ \\
\hline No opinion & $39(55)$ & $24^{\dagger}(22)$ & $62(33)$ \\
\hline Disagree & $3(4)$ & $3(3)$ & $2(1)$ \\
\hline Strongly disagree & $2(3)$ & $3(3)$ & $0(0)$ \\
\hline \multicolumn{4}{|c|}{$\begin{array}{l}\text { I would like my physician to have basic knowledge of CAM or } \\
\text { be able to refer me to someone with more information or } \\
\text { skills in CAM therapies. }\end{array}$} \\
\hline Strongly agree & $17(24)$ & $22(19)$ & $9(5)$ \\
\hline Agree & $42(59)$ & $48(42)$ & $32(17)$ \\
\hline No opinion & $38(54)$ & $27^{\dagger}(24)$ & $56(30)$ \\
\hline Disagree & $2(3)$ & $1(1)$ & $4(2)$ \\
\hline Strongly disagree & $1(2)$ & $2(2)$ & $0(0)$ \\
\hline \multicolumn{4}{|c|}{$\begin{array}{l}\text { I would like my physician to ask me about any current CAM } \\
\text { therapies I use. }\end{array}$} \\
\hline Strongly agree & $10(14)$ & $10(9)$ & $9(5)$ \\
\hline Agree & $37(54)$ & $50^{\dagger}(45)$ & $16(9)$ \\
\hline No opinion & $48(70)$ & $34^{\dagger}(31)$ & $71(39)$ \\
\hline Disagree & $2(3)$ & $1(1)$ & $4(2)$ \\
\hline Strongly disagree & $3(4)$ & $4(4)$ & $0(0)$ \\
\hline
\end{tabular}

Data are \% (n).

${ }^{*} P<.05, \chi^{2}$ test, CAM users vs nonusers.

${ }^{\dagger} P<.01, \chi^{2}$ test, CAM users vs nonusers.

CAM, complementary alternative medicine.

ments and herbs were the most commonly used CAM therapies within the past year, and the use of other CAM therapies aligned with our results. ${ }^{21}$ Thus our sample population's CAM use might correlate with a "West Coast" rather than a Hispanic attitude toward CAM. The popularity of these CAM therapies might be attributed to the mainstream marketing of such products to the general population. It is important for health care providers to recognize the commonality of vitamin and herb use because there are potential adverse interactions between prescription drugs and high-dose vitamins and herbal medicine, including changes in drug efficacy and bioavailability. ${ }^{13}$ Patients who use herbal medicine are more likely to have chronic illnesses for which they concurrently take prescrip- tion medications. ${ }^{22}$ Because patients at highest risk for adverse drug interactions are those with chronic illnesses, ${ }^{13,22}$ primary care providers should inquire about patients' CAM use and accordingly educate patients about the possible risks.

Although most of our surveyed patients identified as Hispanic, most did not practice Hispanic folk medicine, paralleling the results of nationwide studies of Hispanic CAM use. ${ }^{11,23} \mathrm{We}$ might expect folk medicine to be associated with immigrant culture, but most respondents did not use folk medicine regardless of place of birth. Given that there were not any differences in folk medicine use, it follows that patterns of CAM use among US-born and non-US-born Hispanics in our study were similar. There is, however, variation in the literature 
regarding the use of Hispanic folk medicine in smaller-scale studies. Studies conducted in Colorado and Texas revealed prevalent use of folk medicine among Hispanics $\left(40.7 \%{ }^{24}\right.$ and $22.0 \%,{ }^{25}$ respectively). Regional and ethnic differences among the Hispanics in these studies could explain the discrepancy in folk medicine use, and future studies comparing foreign Hispanics of other ethnic backgrounds may be of interest. Although our sample population did not use folk remedies, the literature shows that many patients in the United States incorporate cultural traditions into their health care. Health care providers' cognizance and acknowledgment of these practices can enhance communication with patients and may encourage patients' compliance with conventional medicine.

Our survey showed that the most commonly cited reason for CAM use among both Hispanics and non-Hispanics was weight loss. Mikhail et $\mathrm{al}^{9}$ reported that $23.8 \%$ of Hispanic CAM users chose "overweight" as a reason for CAM use. A nationwide telephone survey showed that $15.2 \%$ of respondents used a weight loss supplement at some point in their life. ${ }^{26}$ Our respondents' aim of losing weight may possibly be linked to obesity. Obesity is highly associated with chronic illnesses such as cardiovascular disease and diabetes. This is of particular relevance to Hispanic populations because, compared with non-Hispanic whites, Hispanics are 1.2 times more likely to be obese and 1.7 times more likely to be diagnosed with diabetes, according to the 2011 National Health Institute Survey. ${ }^{27,28}$ Furthermore, because integrative approaches can be used to address weight control, the presence of the Integrative Medicine residency track and Integrative Medicine consultation service at UC Irvine's FHC might contribute to the interest in weight loss. The Integrative Medicine consultation service focuses on improving health and well-being by advising patients about proper incorporation of therapies such as diet, nutrition, exercise, massage, and mind-body relaxation with conventional medical treatments. In addition, because a large proportion of our respondents indicated using vitamins/supplements and herbs, their attention may be drawn to the "weight loss" category, influencing the results of our study. Still, it is possible that there is a correlation between high vita$\mathrm{min} /$ supplements and herb use and the desire to lose weight among our population. In a study focused on CAM use for weight loss in Mexican
American women, herbs (71\%) were most commonly used to lose weight. ${ }^{29}$ A nationwide study reported that, besides dietary supplements, other CAM therapies are not used for weight loss. ${ }^{30}$

While our population was primarily concerned about weight loss, justification for CAM use is diverse. For example, 2 separate studies conducted in Los Angeles, California, showed that digestive problems ${ }^{17}$ and pain ${ }^{9}$ were the most common reasons for CAM usage. In addition, a study of a Hispanic community in South Carolina reported infection as the main reason for CAM use. ${ }^{31}$ Demographic variations among the sampled populations could explain the differences observed. It is interesting to note, however, that among the 3 studies, only Mikhail et $\mathrm{al}^{9}$ listed weight loss in their survey. The absence of a "weight loss" option on the surveys could have influenced the results of other studies. Because weight control is a growing concern in the United States, it should be considered a health condition in future survey designs. Nevertheless, given the wide-ranging reasons for CAM use, it is important for clinicians to have a broad understanding of the unconventional methods that patients use so they can provide comprehensive medical advice.

Surveyed patients showed a strong interest in having CAM therapies incorporated at the FHC. There is a lack of prior literature exploring the interests of patients from underserved regions in receiving CAM therapies from their primary care providers. Patients in our study most desired therapies associated with diet and lifestyle improvements, which may be correlated with the most common reason for CAM use (weight loss). $\mathrm{Pa}$ tients also were interested in having other specialized CAM therapies offered at the health center, including massage, mind-body relaxation techniques, and acupuncture. Although CAM users showed more interest in incorporating CAM therapies into the clinic, non-CAM users showed some interest as well. Moreover, our study indicated that patients in our population are comfortable with communicating with their health care providers about their CAM use. Yet, prior studies have shown that $>60 \%$ of racial minorities do not disclose their CAM usage to their physicians. ${ }^{11,12}$ In general, the CAM disclosure rate is low across all demographics, as well. ${ }^{11,12,32} \mathrm{~A}$ commonly cited reason for low CAM disclosure rates is that clinicians do not ask patients about CAM use. ${ }^{33,34}$ Our surveyed patients 
might be more comfortable discussing CAM with their physicians because of the influence of the Integrative Medicine residency track and the pilot Integrative Medicine consultation service. If physicians initiate dialog about CAM, patients may be more candid about their use.

Our study had several strengths. First, our sample was generally reflective of the patient population of this Santa Ana health center. Second, both English and Spanish versions of the survey were available to encourage non-English speakers to participate in the study. Third, trained Spanish translators were available to respondents at the time of data collection to further ensure that respondents were offered clearer explanations of the survey questions if necessary. Last, we provided definitions of CAM and the different CAM modalities to remove ambiguity over terms.

There were also some limitations to our study. First, our respondents were sampled from a single health center, so generalizability to other clinics is limited. Second, respondents were not required to answer every question, so our data could be missing information that respondents chose not to disclose. Third, because the survey was voluntary, there may be response bias. Lastly, potential for recall bias should also be considered because respondents selfreported their CAM use.

Future studies should determine patterns of CAM use within different communities and health centers. Considering that some of our population's attitudes toward CAM differed from those studied in the past, it is important to study patient preferences on a more local and focused scale to better individualize treatments to each health center.

\section{Conclusion}

Our survey study showed that patients at the UC Irvine FHC recognize the importance of communicating with their health care providers about their CAM use and seem receptive to further discussion of such topics. Most of the patients in our study indicated that they are open and willing to discuss CAM. If physicians are more proactive in facilitating CAM-related discussions, CAM disclosure rates may increase, which may ultimately improve patient safety and compliance. Because there is a high level of patient interest in CAM resources from their health care provider, health centers and hospitals may want to consider providing select
CAM modalities to their patients. The results and implications of our study may be useful to primary care practices from similar regions that aim to expand the range of care at their clinics.

\section{References}

1. Are you considering complementary medicine? Bethesda, MD: National Center for Complementary and Alternative Medicine; 2006. Updated March 2013. Available from: http://nccam.nih.gov/health/ decisions/consideringcam.htm. Accessed September 26, 2014.

2. Barnes PM, Bloom B, Nahin RL. Complementary and alternative medicine use among adults and children: United States, 2007. Natl Health Stat Report 2008;(12):1-23.

3. Barnes PM, Powell-Griner E, McFann K, Nahin RL. Complementary and alternative medicine use among adults: United States, 2002. Semin Integr Med 2004;2:54-71.

4. Su D, Li L. Trends in the use of complementary and alternative medicine in the United States: 2002-7. J Health Care Poor Underserved 2011;22:296-310.

5. Population estimates. National characteristics: vintage 2012. Suitland, MD: United States Census Bureau; 2012. Available from: https://www.census.gov/popest/ data/national/asrh/2012/index.html. Accessed September 26, 2014.

6. Scheppers E, van Dongen E, Dekker J, Geertzen J, Dekker J. Potential barriers to the use of health services among ethnic minorities: a review. Fam Pract 2006;23:325-48.

7. Mackenzie ER, Taylor L, Bloom BS, Hufford DJ, Johnson JC. Ethnic minority use of complementary and alternative medicine (CAM): a national probability survey of CAM utilizers. Altern Ther Health Med 2003;9:50-6.

8. Hsiao AF, Wong MD, Goldstein MS, et al. Variation in complementary and alternative medicine (CAM) use across racial/ethnic groups and the development of ethnic-specific measures of CAM use. J Altern Complement Med 2006;12:281-90.

9. Mikhail N, Wali S, Ziment I. Use of alternative medicine among Hispanics. J Altern Complement Med 2004;10:851-9.

10. Ortiz BI, Shields KM, Clauson KA, Clay PG. Complementary and alternative medicine use among Hispanics in the United States. Ann Pharmacother 2007;41:994-1004.

11. Graham RE, Ahn AC, Davis RB, O'Connor BB, Eisenberg DM, Phillips RS. Use of complementary and alternative medical therapies among racial and ethnic minority adults: results from the $2002 \mathrm{Na}-$ tional Health Interview Survey. J Natl Med Assoc 2005;97:535-45.

12. Chao MT, Wade C, Kronenberg F. Disclosure of complementary and alternative medicine to conven- 
tional medical providers: variation by race/ethnicity and type of CAM. J Natl Med Assoc 2008;100: 1341-9.

13. Eisenberg DM, Davis RB, Ettner SL, et al. Trends in alternative medicine use in the United States, 1990-1997: results of a follow-up national survey. JAMA 1998;280:1569-75.

14. Fiscella K, Franks P, Gold MR, Clancy CM. Inequality in quality: addressing socioeconomic, racial, and ethnic disparities in health care. JAMA 2000; 283:2579-84.

15. Okoro CA, Zhao G, Li C, Balluz LS. Has the use of complementary and alternative medicine therapies by U.S. adults with chronic disease-related functional limitations changed from 2002 to 2007? J Altern Complement Med 2013;19:217-23.

16. Saydah SH, Eberhardt MS. Use of complementary and alternative medicine among adults with chronic diseases: United States 2002. J Altern Complement Med 2006;12:805-12.

17. White B, Knox L, Zepeda M, Mull D, Nunez F. Impact of immigration on complementary and alternative medicine use in Hispanic patients. J Am Board Fam Med 2009;22:337-8.

18. Loera JA, Black SA, Markides KS, Espino DV, Goodwin JS. The use of herbal medicine by older Mexican Americans. J Gerontol A Biol Sci Med Sci 2001;56:M714-8.

19. Burge SK, Albright TL. Use of complementary and alternative medicine among family practice patients in south Texas. Am J Public Health 2002;92:1614-6.

20. Howell L, Kochhar K, Saywell R, et al. Use of herbal remedies by Hispanic patients: do they inform their physician? J Am Board Fam Med 2006;19:566-78.

21. Goldstein MS, Brown ER, Ballard-Barbash R, et al. The use of complementary and alternative medicine among California adults with and without cancer. Evid Based Complement Alternat Med 2005;2:557-65.

22. Izzo AA, Ernst DE. Interactions between herbal medicines and prescribed drugs: a systematic review. Drugs 2001;61:2163-75.

23. Heathcote JD, West JH, Hall PC, Trinidad DR. Religiosity and utilization of complementary and alternative medicine among foreign-born Hispanics in the United States. Hisp J Behav Sci 2011;33:398408.

24. Padilla R, Gomez V, Biggerstaff SL, Mehler PS. Use of curanderismo in a public health care system. Arch Intern Med 2001;161:1336-40.

25. Martinez LN. South Texas Mexican American use of traditional folk and mainstream alternative therapies. Hisp J Behav Sci 2009;31:128-43.

26. Blanck HM, Serdula MK, Gillespie C, et al. Use of nonprescription dietary supplements for weight loss is common among Americans. J Am Diet Assoc 2007;107:441-7.

27. Obesity and Hispanic Americans. Bethesda, MD: Office of Minority Health, US Department of Health and Human Services; 2012. Available from: http://minorityhealth. hhs.gov/omh/browse.aspx?lvl=4\&lvlID =70/. Accessed September 26, 2014.

28. Diabetes and Hispanic Americans. Bethesda, MD: Office of Minority Health, US Department of Health and Human Services; 2013. Available from: http://minorityhealth. hhs.gov/omh/browse.aspx?lvl=4\&lvlid=63/. Accessed September 26, 2014.

29. Lindberg NM, Stevens VJ, Elder C, Funk K, Debar L. Use of alternative medicine for weight loss among Mexican-American women. J Immigr Minor Health 2013;15:982-5.

30. Sharpe PA, Blanck HM, Williams JE, et al. Use of complementary and alternative medicine for weight control in the United States. J Altern Complement Med 2007;13:217-22.

31. Trangmar P, Diaz VA. Investigating complementary and alternative medicine use in a Spanish-speaking Hispanic community in South Carolina. Ann Fam Med 2008;6(Suppl 1):s12-5.

32. Planta M, Gundersen B, Petitt JC. Prevalence of the use of herbal products in a low-income population. Fam Med 2000;32:252-7.

33. Shelley BM, Sussman AL, Williams RL, Segal AR, Crabtree BF, Rios Net Clinicians. 'They don't ask me so I don't tell them': patient-clinician communication about traditional, complementary, and alternative medicine. Ann Fam Med 2009;7:139-47.

34. Eisenberg DM, Kessler RC, Van Rompay MI, et al. Perceptions about complementary therapies relative to conventional therapies among adults who use both: results from a national survey. Ann Intern Med 2001;135:344-51. 